\title{
Arrhythmogenic Right Ventricular Cardiomyopathy or Dilated Cardiomyopathy associated with Partial Hypopituitarism
}

\author{
Hao Thai Phan \\ Department of Internal Medicine. Pham Ngoc Thach University of Medicine, Ho Chi Minh City, Vietnam.
}

\begin{abstract}
Corresponding Author:
Dr. Hao Thai Phan

Email: phanthaihao@yahoo.com

This is an Open Access article distributed under the terms of the Creative Commons Attribution License (creativecommons.org/ licenses/by/3.0).
\end{abstract}

Received Accepted

Published

September 15, 2017

January 30, 2018

February 5, 2018

\begin{abstract}
Background: Arrhythmogenic right ventricular cardiomyopathy (ARVC), also known as arrhythmogenic right ventricular dysplasia, is a heritable heart-muscle disorder that predominantly affects the right ventricle. Progressive loss of right ventricular myocardium and its replacement by fibrofatty tissue is the pathological hallmark of the disease. Case Report: A 25-year-old female presented with dyspnea from last one year. Her symptoms included fatigue, weakness, inability to lose weight, puffiness, and constipation. Echocardiogram and cardiac MRI were consistent with diagnostic criteria of ARVC formulated in 2010 by the revisited Task Force, with two major or one major and two minor criteria or four minor criteria. Conclusion: Cardiac magnetic resonance (MRI) is considered the best imaging modality in evaluating the RV in ARVC.
\end{abstract}

Keywords: Arrhythmogenic Right Ventricular Dysplasia, Dyspnea, Echocardiography, Heart Ventricles, Magnetic Resonance Imaging.

\section{Introduction}

Arrhythmogenic right ventricular cardiomyopathy (ARVC), also known as arrhythmogenic right ventricular dysplasia, is a heritable heart-muscle disorder that predominantly affects the right ventricle. ARVC is one of the leading causes of arrhythmic cardiac arrest in young people and athletes. First it was described by Marcus and colleagues in 1982, describing 24 affected patients [2]. The disease was initially designated as a dysplasia because it was thought to be a congenital defect in the development of the right ventricular myocardium. The subsequent discovery that the disease is caused by a genetic defect in the cardiac desmosomes has led to its recognition as a cardiomyopathy and its inclusion in the classification of cardiomyopathies by the American Heart Association [3]. We present a clinical case of arrhythmogenic right ventricular cardiomyopathy associated with partial hypopituitarism from previous intracranial surgery.

\section{Case Report}

A 25-year-old female presented with dyspnea for last one year. She was diagnosed as systemic lupus erythematosus by a hospital in our city one year ago. Her symptoms included fatigue, weakness, inability to lose weight (or weight gain), puffiness, and constipation. She did not attain menarche. Physical examination showed periorbital puffiness, brittle hair and eyebrow loss. She had a past history of brain tumor 17 years ago at the age of 8 years. Her treatment for brain tumor was surgery, chemotherapy and radiation therapy. Subsequently she stopped taking medicines and treatment plan as per her family decision.

Chest X-ray demonstrated increased heart-thorax index [Fig.1]. ECG showed right axis deviation, and incomplete right bundle block [Fig.2]. This prompted further endocrine workup that revealed the presence of hypoadrenalism, hypogonadism and growth hormone deficiency. 
Partial hypopituitarism from previous intracranial surgery was diagnosed [Table 1]. Transthoracic echocardiogram showed normal left ventricular systolic function with ejection fraction of $53 \%$, normal size and wall thickness of the left ventricle, slightly dilated left atrium, enlargement of the right ventricle $50 \mathrm{~mm}$ and right ventricular outflow tract $47 \mathrm{~mm}$ with reduced contractile function, tricuspid annular plane systolic excursion (TAPSE) $11 \mathrm{~mm}$, apical, aneurysm-akinesia, endocardial ventricular hypertrabeculation especially at apex; mild mitral regurgitation and severe tricuspid regurgitation; and medium pericardial effusion without right ventricular depression [Fig.3]. Cardiac MRI showed normal volume and function of the left ventricle (EF 55\%), right ventricle with $114 \mathrm{ml} / \mathrm{m}^{2}$ indexed end-diastolic volume, reduced right ventricular function (EF 29.6\%), areas of dyskinesia of the free wall at the mid and apex; late gadolinium enhancementof the free wall right ventricle at the mid and apex; hypertrabeculation of septal wall at the apex; medium pericardial effusion, no cardiac tamponade [Fig.4]. ARVC was diagnosed on the basis of revised 2010 task force criteria for ARVCas mentioned in Table 2 [7].

Differential diagnosis is dilated cardiomyopathy associated with partial hypopituitarism. If hypopituitarism promptly

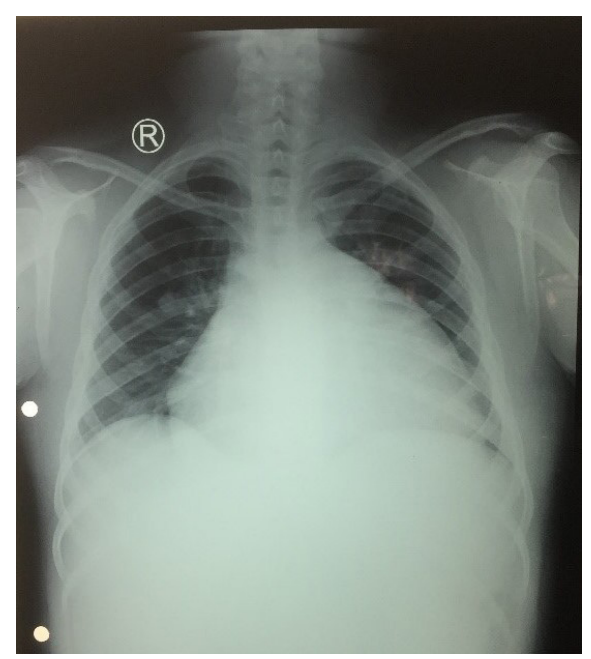

Fig.1: Chest $X$-ray showed cardio-thoracic ratio $>0.5$. responds to multiple hormone replacement therapy, definite diagnosis would be dilated cardiomyopathy associated with partial hypopituitarism.

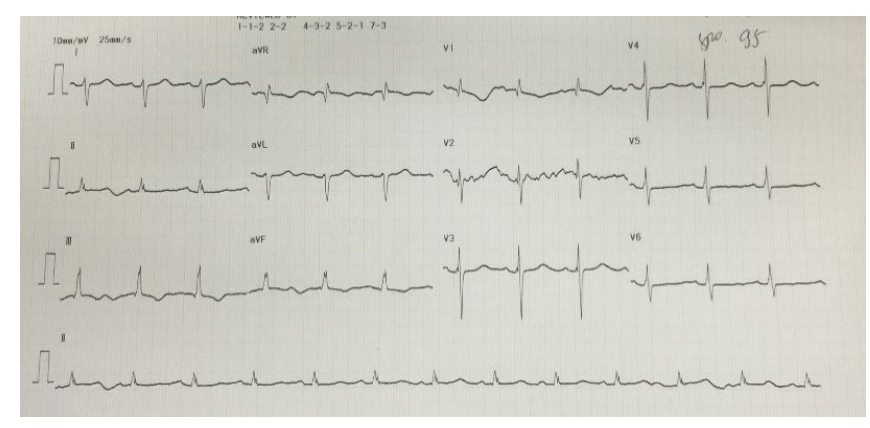

Fig.2: ECG showed right axis deviation, and incomplete right bundle block.

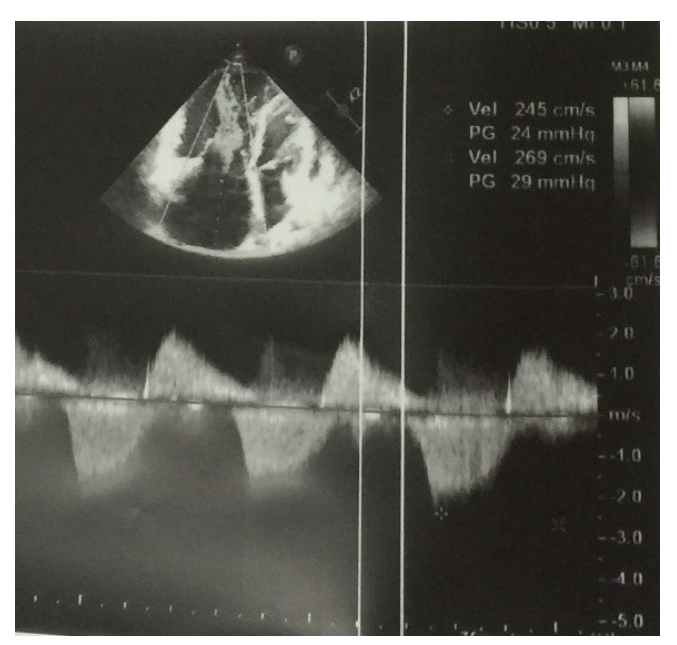

Fig.3: Doppler flow through triscupid valve.

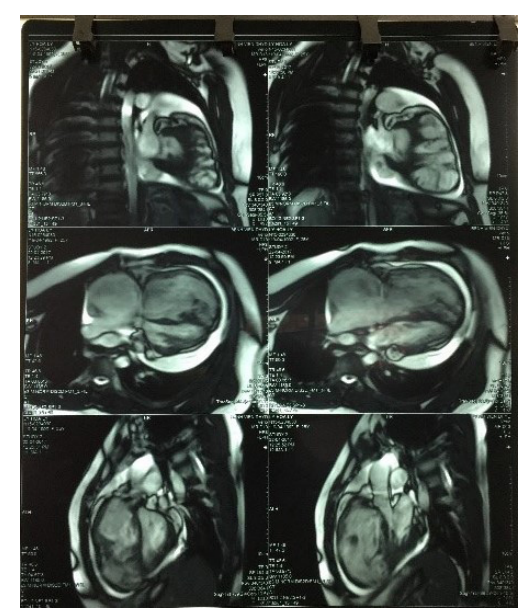

Fig.4: Cardiac MRI showed hyper-trabeculation of septal wall at the apex. 
Table 1: Laboratory findings.

\begin{tabular}{|l|l|l|}
\hline & Results & Normal Value \\
\hline Insulin like growth factor 1 & $<25$ & $100-350 \mathrm{ng} / \mathrm{mL}$ \\
\hline Adrenocorticotrophic hormone & 2.62 & $7.2-63.3 \mathrm{pg} / \mathrm{mL}$ \\
\hline $\begin{array}{l}\text { Anti microsomal antibody } \\
\text { (TPOAb) }\end{array}$ & 15.75 & $<34 \mathrm{U} / \mathrm{L}$ \\
\hline Follicle stimulating hormone & 0.616 & $3-153 \mathrm{mUI} / \mathrm{mL}$ \\
\hline Leutinizing hormone & $<0.1$ & $2-64 \mathrm{mUI} / \mathrm{mL}$ \\
\hline Prolactin & 17.8 & $6-30 \mathrm{ng} / \mathrm{mL}$ \\
\hline Estradiol (E2) & $<5$ & $12.5-650 \mathrm{pg} / \mathrm{mL}$ \\
\hline Progesterone & $<0.03$ & $4-25 \mathrm{ng} / \mathrm{mL}$ \\
\hline Human growth hormone & $<0.05$ & $<8 \mathrm{ng} / \mathrm{mL}$ \\
\hline
\end{tabular}

\section{Discussion}

ARVC causes $11-22 \%$ of sudden cardiac death in the young athletes patient population, resulting in approximately $22 \%$ of cases in athletes in northern Italy [4] and about $17 \%$ of sudden cardiac death in young people in the United States [5]. The pathologic hallmark of disease is myocardial atrophy (myocyte loss), fibrofatty replacement, fibrosis and thinning of the wall with chamber dilation and aneurysm formation [6]. The genetics of the disease seems to support the hypothesis that it may be caused by desmosomal dysfunction (mutation of plakophilin-2, desmoglein-2, desmocollin-2, desmoplakin genes), that lead to impaired mechanical and electrical coupling between individual cells, leading to myocyte uncoupling, especially under conditions that increase myocardial strain, for example during physical effort.

Diagnosis of ARVC relies on a scoring system, formulated in 2010 by the revisited Task Force, with two major or one major and two minor criteria or four minor criteria based on the demonstration of a combination of defects in right ventricular morphology and function, characteristic depolarization/repolarization electrocardiogram abnormalities (negative $\mathrm{T}$ waves and/or "epsilon" waves in right precordial leads), characteristic tissue pathology, typical arrhythmias, family
Table 2: 2D Echo Criteria of ARVC as per revised 2010 task force criteria.

\begin{tabular}{|c|}
\hline Major \\
\hline $\begin{array}{l}\text { Regional RV akinesia, dyskinesia, or aneurysm AND one of the } \\
\text { following measured at end diastole: }\end{array}$ \\
\hline - PLAX RVOT $\geq 32 \mathrm{~mm}\left(\mathrm{PLAX} / \mathrm{BSA} \geq 19 \mathrm{~mm} / \mathrm{m}^{2}\right)$, or \\
\hline - PSAX RVOT $\geq 36 \mathrm{~mm}\left(\mathrm{PSAX} / \mathrm{BSA} \geq 21 \mathrm{~mm} / \mathrm{m}^{2}\right)$, or \\
\hline - Fractional area change $\leq 33 \%$ \\
\hline Minor \\
\hline $\begin{array}{l}\text { Regional RV akinesia or dyskinesia or dyssynchronous RV } \\
\text { contraction AND one of the following measured at end diastole: }\end{array}$ \\
\hline $\begin{array}{l}-\operatorname{PLAX} \text { RVOT } \geq 29 \text { to }<32 \mathrm{~mm} \quad(\mathrm{PLAX} / \mathrm{BSA} \geq 16 \text { to } \\
\left.<19 \mathrm{~mm} / \mathrm{m}^{2}\right) \text {, or }\end{array}$ \\
\hline $\begin{array}{l}-\operatorname{PSAX} \text { RVOT } \geq 32 \text { to }<36 \mathrm{~mm} \quad(\mathrm{PSAX} / \mathrm{BSA} \geq 18 \text { to } \\
\left.<21 \mathrm{~mm} / \mathrm{m}^{2}\right) \text {, or }\end{array}$ \\
\hline - Fractional area change $>33 \% \leq 40 \%$ \\
\hline
\end{tabular}

history, and the results of genetic testing [7]. Cardiac magnetic resonance (MRI) is considered the best imaging modality in evaluating the RV in ARVC and provides tissue characterization and identification of intra-myocardial fat and fibrosis in addition to assessment of ventricular structure and function.

\section{Conclusion}

Cardiac magnetic resonance (MRI) is considered the best imaging modality in evaluating the RV in ARVC and provides tissue characterization and identification of intramyocardial fat and fibrosis in addition to assessment of ventricular structure and function.

Contributors: HTP wrote the manuscript, did literature search, involved in patient management, and approved the final version of this article. He will act as guarantor of the study.

Funding: None; Competing interests: None stated.

\section{References}

1. Thiene G, Nava A, Corrado D, Rossi L, Pennelli N. Right ventricular cardiomyopathy and sudden death in young people. N Engl J Med. 1988;318:129-133.

2. Marcus FI, Fontaine GH, Guiraudon G, Frank R, Laurenceau JL, Malergue C, et al. Right ventricular dysplasia: a report of 24 adult cases. Circulation. 1982;65:384-398. 
3. Maron BJ, Towbin JA, Thiene G, Antzelevitch C, Corrado D, Arnett D, et al. Contemporary definitions and classification of the cardiomyopathies: an American Heart Association Scientific statement from the council on clinical cardiology, heart failure and transplantation committee; quality of care and outcomes research and functional genomics and translational biology interdisciplinary working groups; and council on epidemiology and prevention. Circulation. 2006;113:1807-1816.

4. Corrado D, Fontaine G, Marcus FI, McKenna WJ, Nava A, Thiene G, et al. Arrhythmogenic right ventricular dysplasia/cardiomyopathy: need for an international registry. Study Group on arrhythmogenic right ventricular dysplasia/cardiomyopathy of the working groups on myocardial and pericardial disease and arrhythmias of the European Society of cardiology and of the scientific council on cardiomyopathies of the world heart federation. Circulation. 2000;101:E101-E106.

5. Dalal D, Nasir K, Bomma C, Prakasa K, Tandri H, Piccini $\mathrm{J}$, et al. Arrhythmogenic right ventricular dysplasia: a United States experience. Circulation. 2005;112:38233832.

6. Thiene G, Basso C, Danieli G, Rampazzo A, Corrado D, Nava A. Arrhythmogenic right ventricular cardiomyopathy a still underrecognized clinic entity. Trends Cardiovasc Med. 1997;7:84-90.

7. Marcus FI, McKenna WJ, Sherrill D, Basso C, Bauce $\mathrm{B}$, Bluemke DA, et al. Diagnosis of arrhythmogenic right ventricular cardiomyopathy/dysplasia: proposed modification of the task force criteria. Circulation. 2010;121:1533-1541. 